\title{
Competencias legislativas del Estado y de las Comunidades Autónomas en la regulación del sistema tributario local
}

\author{
Casimiro López García \\ Secretario e Interventor-Tesorero de Administración Local \\ Ayuntamiento de Torrelavega
}

\begin{abstract}
Sumario: I. NATURALEZA Y CONCEPTO DE LA AUTONOMÍA LOCAL EN LA CE. $1^{\circ}$ la autonomía local: poder público limitado y definido por la ley. identidad de sustancia entre las autonomías territoriales. II. PRINCIPIOS DE AUTONOMÍA Y SUFIFICIENCIA FINANCIERA DEL REGIMEN LOCAL. 1. La autonomía financiera en el orden local. III. AUTONOMIA TRIBUTARIA LOCAL. IV. RESERVA DE LEY Y AUTONOMÍA TERRITORIAL. 1. Alcance de la Reserva de Ley en el establecimiento de los tributos locales. 2. Reserva de ley: principios y finalidades. 3. Necesidad de previa regulación por Ley del Estado. 4. Imposibilidad de cláusulas habilitadoras. 5. Necesaria predeterminación y encuadramiento por Ley del Estado del Poder Tributario Local. V TITULOS COMPETENCIALES DE LAS COMUNIDADES AUTONOMAS EN MATERIA DE TRIBUTOS LOCALES (SISTEMA TRIBUTARIO). 1. Vaciado de competencias. 2. Concepto unitario de la materia Régimen Local. 3. Alcance del concepto bases 149.1.18 CE. VI. TITULOS COMPETENCIALES DEL ESTADO. 1. Hacienda general 149.1.14 CE. 2. Relación Especial entre el artículo 133.2 CE y el artículo 149.1.14 CE. 3. Poderes normativos y de ordenación que atribuye al Estado el artículo 133.1 CE. 4. Reserva de ley en materia tributaria y principio de igualdad en la CE de 1978. VII EVOLUCION DE LA DOCTRINA DEL TC. 1. Unidad del título competencial Régimen Local. 2. Separación entre competencias financieras y otras: la materia financiera no es una competencia. 3. Funciones y alcance de la Reserva de Ley. CONCLUSIONES.
\end{abstract}

\section{NATURALEZA Y CONCEPTO DE LA AUTONOMÍA LOCAL EN LA CE}

De acuerdo con Luciano Parejo Alfonso, se puede afirmar que el artículo 137 de la Constitución Española (CE) de 1978 configura a la Autonomía como el principio general de la organización territorial del poder político, que caracteriza así la propia naturaleza y estructura del Estado, integrado por Comunidades Autónomas, Municipios y Provincias. Las Comunidades Autónomas a su vez están amparadas y reconocidas con un derecho garantizado en el artículo $2 \mathrm{CE}$, que se extiende a las Nacionalidades y Regiones integrantes de la Nación española, y a los distintos territorios con derechos históricos y otras particularidades en las disposiciones adicionales y transitorias de la CE. Se trata del principio que conforma y caracteriza nuestro Sistema Constitucional, cuya modifica- 
ción requiere el quorum reforzado exigido por el artículo 168 de la Constitución ${ }^{1}$.

La autonomía local aparece configurada como autogobierno de las correspondientes colectividades en los artículos 140 a 142, y la definición de su contenido y alcance a merced de lo dispuesto en las Leyes. Teniendo en cuenta que el legislador esta vinculado de forma más fuerte que en otros desarrollos directos de la Constitución por estar afectado el propio ser del Estado del que forma parte y al que también conforman los Municipios, las Islas, las Nacionalidades, y las Regiones. La eficacia reforzada propia de la previsión constitucional de la autonomía local — añade el profesor Parejo Alfonso en el desarrollo de sus tesis sobre la garantía institucional de la Administración Local en la Constitución Española- consiste técnicamente en la garantía objetiva de la presencia y la actuación permanentes de la institución en el ordenamiento del Estado en su conjunto, es decir, en una garantía institucional, en la forma y manera en que se definió para el reconocimiento y defensa de los derechos fundamentales en el Derecho Público alemán.

La Garantía institucional de la Administración Local tal como ha sido concebida y definida por el profesor Francisco Sosa Wagner ${ }^{2}$ no incluye un listado de competencias mínimas garantizadas, sino que queda al albur de la concreta definición de su ser, contenido y actividades que se establezca en cada caso por las leyes del Estado o de las Comunidades Autónomas. La Autonomía Local se define así por el TC como un sistema de carácter bifronte (sentencia de 23 de diciembre de 1982), que la concibe como un sistema derivado, de acuerdo con el esquema constitucional de distribución de competencias. Existe así una obligación constitucional de permanencia de la institución, pero no una garantía de contenido mínimo³.

\section{La autonomía local: poder público limitado y definido por la ley. Identidad de sustancia entre las autonomías territoriales}

La autonomía local así configurada hace referencia a un poder limitado, cuyo ámbito corresponde precisar a la Ley, STC de 2 de febrero de 1981, y tiene o se configura - para aquella primera doctrina constitucional— como

\footnotetext{
${ }^{1}$ Luciano Parejo Alfonso, REALA, 229, enero marzo de 1986: «...como tal, goza de la eficacia inmediata y trascendente a la totalidad del ordenamiento jurídico propia de los principios generales del Derecho y que está claramente conectado — en un sistema con distribución horizontal del Poder, según diseño de los artículos 1 y 2 de la Constitución- con el pluralismo político, es decir, con uno de los valores superiores del ordena constitucional, directamente entroncado a la caracterización esencial del Estado como social y democrático de Derecho y, por tanto, a la filosofía última o nuclear de dicho orden».

${ }^{2}$ Francisco Sosa WAgner, «La Autonomía Local», REALA, 240, octubre-diciembre de 1988

${ }^{3}$ L. PAREJo, Garantía Institucional u Autonomías Locales, IEAL, Madrid 1981, pp. 146 y ss. Relaciona la Automía local con el principio democrático-representativo, artículos 9, y $23 \mathrm{CE}$.
} 
de naturaleza más administrativa que política. No es igual la Autonomía Municipal que la Autonomía de las Nacionalidades y Regiones en la Constitución Española. Están diferenciadas por el muy distinto alcance del poder que implican. Las Comunidades Autónomas tienen poder superior por gozar de una mayor capacidad de configuración social, como lo atestigua el hecho de ser titulares de una potestad plenamente legislativa, que no se atribuye ni reconoce en principio a los Entes locales. El poder legislativo con mayúsculas, una vez establecidas, consolidadas y ampliadas, tras sucesivos pactos de Estado, las Comunidades Autónomas, y más ahora que nos encontramos ante un tercer proceso de concesión de mayor poder político y financiero a las Comunidades Históricas que se verán reconocidas como «naciones» en las reformas de sus respectivos Estatutos de Autonomía, está dividido entre el Estado y las Comunidades Autónomas, según el reparto de los distintos títulos competenciales que efectúa la Constitución en los artículos 148 y 149, y suele plasmarse en la mayoría de los títulos conforme a la técnica de legislación básica del Estado artículo 149.1.18 CE, legislación de desarrollo de las Comunidades Autónomas que tengan asumida la competencia en su respectivo Estatuto, y siempre conforme a lo dispuesto en la Ley de Bases del Régimen Local que, como lo son las Leyes Orgánicas, también es medida de constitucionalidad, STC de 27 febrero de 1987. Sin que se reconozca o parezca posible un tercer nivel legislativo a establecer a favor de los Entes Locales. Ambos legisladores están obligados a concretar en cada caso el interés local ${ }^{4}$.

\section{PRINCIPIOS DE AUTONOMÍA Y SUFIFICIENCIA FINANCIERA DEL RÉGIMEN LOCAL}

Ferreiro define la autonomía financiera como el reconocimiento de unos recursos propios y la respectiva capacidad de decisión sobre el empleo de estos recursos $^{5}$. La autonomía financiera que reconoce la Constitución integra, a juicio de Herrera, las siguientes notas: poder para establecer y exigir tributos, suficiencia de medios, poder para configurar los recursos de sus sistemas financiero y poder presupuestario.

La Autonomía financiera hace referencia al obligado reconocimiento de un margen de libertad en la definición de los tributos propios y en la disponibilidad de medios suficientes para ejercer las competencias propias ${ }^{6}$. La

\footnotetext{
${ }^{4}$ SSTC de 7 de abril, 28 de junio y 3 de agosto de 1983.

5 Alfonso Ojeda Martín, «El Ámbito de la Autonomía Finaniera en las Provincias y Municipios», REALA, $\mathrm{N}^{\circ} 255-256$, julio octubre de 1992, pp. 167 y siguientes.

${ }^{6}$ Simón Acosta concibe la autonomía financiera como libertad en el desarrollo de la actividad financiera. En cambio, MARTín QueRALT prefiere subrayar la «disponibilidad de medios y libertad para asignar los mismos a unos determinados fines».
} 
Autonomía Financiera, más que una nota o aspecto de un concepto general de Autonomía Local es un concepto instrumental, y hace referencia a la materia Hacienda como algo distinto, previo y separado del propio Régimen Local, e incluso de los sistemas constitucionales de distribución de competencias: no es una materia sobre la que atribuir competencias.

La Carta Europea de la Autonomía Local configura la autonomía financiera en una acepción instrumental: incorpora el derecho a decidir sobre la cuantía y el importe de unos recursos propios, que deben ser suficientes para dar cobertura a una política propia de gasto. Este concepto «material» 0 «instrumental» también se encuentra en el artículo $156 \mathrm{CE}$ para las Comunidades Autónomas, y viene a ser el presupuesto o condición necesaria de cualquier autonomía territorial. Las analogías y similitudes no terminan aquí, el artículo 9 CEAL estipula que las entidades locales tienen derecho a tener «recursos propios suficientes de los cuales pueden disponer libremente en el ejercicio de sus competencias», en una dicción similar a lo dispuesto en el artículo $142 \mathrm{CE}$.

Javier GARCía RoCA ${ }^{7}$ sintetiza los principios que, sobre la autonomía financiera, establece la CEAL, que parece presidido por el principio de proporcionalidad entre medios y competencias o correspondencia entre medios y fines. El principio de suficiencia se debe plasmar en un sistema diversificado y evolutivo que cuente con medios propios suficientes - con potestad para establecer la cuota y el tipo- para mantener los niveles de prestación de servicios ${ }^{8}$.

La Constitución de 1978 sólo atribuye autonomía financiera expresa a las Comunidades Autónomas en el artículo 156.1 CE. Falta el mismo reconocimiento constitucional expreso a favor de los Entes Locales. La doctrina se interrogó sobre el alcance de esta omisión, al resultar manifiesto que tanto podía deberse a una voluntad de exclusión, como a tratarse - la autonomía financiera - de un aspecto o contenido más de la Autonomía Territorial.

\footnotetext{
${ }^{7}$ REALA, no 282 , pp. 45 y 46.

${ }^{8}$ Art. 9 CEAL.
}

La proporcionalidad entre recursos financieros y competencias; La presencia de unos ingresos patrimoniales y tributos locales pareja a una «potestad de fijar la cuota y el tipo dentro de los límites de la Ley»;

Un sistema financiero suficientemente diversificado y evolutivo como para permitir a las entidades locales seguir la evolución de los costes de sus competencias;

La adopción de procedimientos de compensación financiera respecto de los entes locales financieramente más débiles;

Un derecho de consulta sobre las modalidades de adjudicación de los recursos distribuidos;

Las subvenciones concedidas no deben estar afectadas, en la medida de lo posible, a proyectos específicos;

Un derecho de acceso, en el marco legal, al mercado nacional de capitales. 
COMPETENCIAS LEGISLATIVAS DEL ESTADO Y DE LAS COMUNIDADES AUTÓNOMAS...

Los intentos de fundamentar la autonomía financiera local en el artículo $142 \mathrm{CE}$ resultaron vanos, por no ser la una presupuesto inexcusable de la otra. El Tribunal Constitucional ya advirtió en su conocida Sentencia de 2 de febrero de 1981 que «la Constitución no garantiza a las Corporaciones locales una autonomía económico-financiera en el sentido de que dispongan de medios propios - patrimoniales y tributarios - suficientes para el cumplimiento de sus fines». Posición que se va a mantener en la sentencia de fecha, 19 de septiembre de 1985, «...en lo relativo a las Haciendas Locales es el principio de suficiencia, y no el de autonomía, el formulado expresamente por el artículo 142 de la Constitución...». Y que no variará hasta la Sentencia $19 / 87$, y siguientes que van a reconocer ya abiertamente la plena vigencia y efectividad de la autonomía financiera local y van a definir su contenido y alcance.

La Constitución obliga al Estado a dotar de medios suficientes a las Haciendas Locales, que tiene que realizarse obligatoriamente - se constitucionaliza también el sistema de financiación de las Corporaciones Locales-, a través de un sistema tributario propio y de la participación «suficiente» en los Tributos del Estado y de las Comunidades Autónomas. Puede afirmarse así con Ferreiro que la propia Constitución establece las directrices del Sistema Financiero y Tributario Local, y más que las directrices, puede añadirse que, en realidad, obliga al Estado a «garantizar», a través de un sistema tributario autónomo, que tiene que administrarse de acuerdo con los principios de autonomía y responsabilidad la suficiencia financiera local. Será obligatorio garantizar un margen para la decisión política de los Gobiernos Locales en materia financiera y tributaria.

\section{AUTONOMÍA TRIBUTARIA LOCAL}

Los principios constitucionales de autonomía y suficiencia financiera de las Entidades Locales tienen y pueden verse en una relación especial y complementaria. La suficiencia es un mandato constitucional, que tiene su causa en la penuria tradicional de la Hacienda Local, para cuya satisfacción la propia CE en el mismo artículo $142^{9}$ articula las fuentes y la estructura ponderada del peso real que ha de tener cada una en la financiación local ${ }^{10}$.

La más reciente doctrina constitucional, entre otras la STC 48/2004, abandona definitivamente las superadas tesis del supuesto enfrentamiento u oposición de los principios de suficiencia y autonomía financiera, para reconocer ya abiertamente que el principio de suficiencia financiera es instrumental — condición necesaria, diríamos nosotros- de cualquier autonomía territo-

\footnotetext{
9 Ferreiro Lapatza, J.J., «La financiación de las Entidades Locales en Cataluña». Revista Española de Derecho Financiero, núm. 45.

${ }^{10}$ STC 48/2004, de 5 de marzo.
} 
rial. En especial de una Autonomía Local cuya naturaleza política sigue en discusión, y que en cualquier caso carece de poder normativo para diseñar un sistema tributario propio que garantice esa suficiencia. Será el Estado —así lo reconoce también abiertamente la citada STC 48/2004- el garante de la suficiencia financiera.

La suficiencia financiera de las Corporaciones Locales es el primer aspecto de la Autonomía para el Tribunal Constitucional. Garantizar la suficiencia de los medios financieros es y será así una responsabilidad del Estado, que está obligado a diseñar una Hacienda Local según los mandatos constitucionales ${ }^{11}$, a través de un sistema tributario propio, que por definición tiene que gozar de autonomía —artículos 137 y 140 CE-, en el sentido genuinamente financiero de «poder de decisión» que materialice el poder político que corresponde al Gobierno Local, que tiene que responsabilizarse de la financiación del gasto, y de la participación en los tributos del Estado y/o de las Comunidades Autónomas.

La existencia de un Sistema Tributario propio de las Entidades Locales está directamente garantizado por la Constitución Española como exigencia de su Autonomía Política, que deberá enmarcarse en la legislación del Estado, que aparece así cada vez más en la doctrina constitucional como «garante» de esa autonomía financiera local de la que la suficiencia es condición previa y necesaria. Determinar cuáles sean los títulos competenciales que la CE otorga al Estado para establecer un Régimen Financiero Local, y cuál pueda ser el alcance de la competencia de las Comunidades Autónomas en tal definición y en qué poderes o facultades se ha de concretar la autonomía local no es tarea fácil ni está terminada, y está condicionada por otros principios constitucionales. Teniendo en cuenta siempre que el sistema constitucional español de distribución territorial del poder engloba realidades políticas muy distintas, que al final pueden determinar un cuadro con distintos actores: integrados, asociados, pactados, que pueden tener distintas competencias en Régimen Local.

Por lo que se refiere a otros principios constitucionales, el art. $31 \mathrm{CE}$ establece una serie de principios materiales y formales que condicionan el ejercicio del poder tributario de los distintos niveles de gobierno, entre los que se encuentra el de la legalidad o reserva de ley, reafirmado respecto de las Corporaciones locales, en el art. 133.2 CE, que gozan de un poder tributario derivado. Y precisamente en virtud de la interpretación dada por la jurisprudencia constitucional a la reserva de ley en materia tributaria, cabe afirmar que el papel que cumplen los tributos propios al servicio de la suficiencia se encuentra, en lo fundamental, predeterminado por el propio legislador estatal.

La CE reconoce a las Corporaciones locales del poder de «establecer y exigir tributos, de acuerdo con la Constitución y las leyes» (art. 133.2), con-

${ }^{11}$ Art. 142 CE. 
COMPETENCIAS LEGISLATIVAS DEL ESTADO Y DE LAS COMUNIDADES AUTÓNOMAS...

firiendo así a dicho poder un rango constitucional que impide su desconocimiento por el Estado o por las Comunidades Autónomas, y es la efectiva garantía de su existencia, aunque tal poder no pueda ser originario, al identificarse este poder originario para establecer tributos con la soberanía del Estado, que reside en el pueblo Español del que emanan todos los poderes del Estado ${ }^{12}$.

No faltan autores que han calificado de originario este poder local, pero se trata de una punto de vista que sólo pretende resaltar su atribución directa por la constitución. Lo que impide que dicho poder quede al arbitrio del legislador estatal o autonómico, cuyas previsiones no podrían en ningún caso vaciar de contenido el precepto constitucional que atribuye a las Entidades Locales el establecimiento y exigencia de tributos. El ejercicio del poder tributario local habrá de ejercerse de acuerdo con la ley. Lo que es tanto como sujetarlo a los principios que establece el propio artículo 31.3 CE: «sólo podrán establecerse prestaciones patrimoniales de carácter público»—categoría en la que, sin duda, se incluyen los tributos- «con arreglo a la ley». El alcance de la reserva de ley afecta directamente a la autonomía financiera local, al resultar evidente que las exigencias y condiciones de tal reserva no pueden cumplirse directamente por las entidades locales sin la «interpositio legis», en principio, del Estado.

\section{RESERVA DE LEY Y AUTONOMÍA TERRITORIAL}

Las relaciones entre los principios de reserva de Ley y Autonomía territorial de los Entes Locales se han estudiado por la jurisprudencia constitucional, en las SSTS 179/1985, de 19 de diciembre, y 19/1987, de 17 de febrero. El TC ha buscado integrar ambos principios constitucionales, de tal manera que la presencia necesaria e irrenunciable de la reserva de ley (31 CE) no desplace al principio de Autonomía Local. La necesaria e ineludible integración se abordará con un sistema que, más que distribuir, reserva al Estado la regulación del Sistema Tributario Local, que enmarca las competencias a reservar a favor de las Corporaciones Locales en materia de señalamiento de bases y tipos, dentro de la previa escala definida por la Ley del Estado. Será la previa Ley del Estado la que defina el ámbito real y efectivo de la de la Autonomía Tributaria Local.

Esta doctrina se alumbrará por el TC en el enjuiciamiento de la Ley 24/ 1983, de 21 de diciembre, de Medidas Urgentes de Saneamiento y regulación de las Haciendas Locales, que trae su causa y justificación en el tan citado mandato constitucional de suficiencia del artículo $142 \mathrm{CE}$, y como añade el propio TC en las competencias/obligaciones del Estado en materia de equi-

${ }^{12}$ Artículos 1.2 y 2 CE. 
librio interterritorial y desarrollo armónico entre las diversas partes del territorio nacional: «la garantía del equilibrio económico, a través de la política económica general, de acuerdo con lo establecido en los arts. 40.1, 131 y 138 de la Constitución, corresponde al Estado, que es el encargado de adoptar las medidas oportunas tendentes a conseguir la estabilidad económica interna y externa, así como el desarrollo armónico entre las diversas partes del territorio español». El TC no asume abiertamente esta nueva consideración del mandato de suficiencia de las Haciendas Locales hasta la S 233/99, que consolidará definitivamente en la reciente $S$ 48/2004.

Desde este punto de vista, el Estado tendrá un título competencial añadido en la definición del sistema tributario local en su condición de «garante» de la suficiencia financiera de la Hacienda Local, y en el ejercicio de las competencias que le corresponden en materia de dirección de la política económica general, y también como garante del equilibrio económico y del desarrollo armónico entre las diversas partes del territorio nacional. Materias de dirección política y de coordinación que no son ni pueden ser delegadas ni transferidas a las Comunidades Autónomas por constituir el fundamento último de todo sistema con el poder político territorializado.

\section{Alcance de la Reserva de Ley en el establecimiento de los tributos locales}

El concepto constitucional de la Reserva de Ley en materia tributaria lleva al TC en la S 179/85 a «...estimar contraria a la reserva de Ley en materia tributaria la remisión en blanco que la Ley impugnada (arts. $8 .{ }^{\circ} 1$ y $9 .{ }^{\circ} 1$ ) hace a los acuerdos de los Ayuntamientos, en lo referente a la fijación del tipo de gravamen a aplicar».

El alcance del principio de reserva de ley y sus distintas finalidades en materia de tributos locales se establecerá por el TC en la S 19/1987, de 17 de febrero. En esta Sentencia abordará los principios, finalidades y efectos que ha de tener la reserva de ley en un Estado con el poder político territorializado. Para el TC, la reserva de Ley en materia tributaria es una consecuencia de la igualdad de todos los ciudadanos (artículo $14 \mathrm{CE}$ ) y sirve para preservar la paridad básica de posición de todos los ciudadanos, y de la unidad misma del ordenamiento. Al mismo tiempo, esta unidad del ordenamiento tributario se ha de poner al servicio de los principios constitucionales de dirección de la política económica a favor del desarrollo económico y de la consecución de un crecimiento estable y de la coordinación entre los distintos territorios del Estado, siempre dentro de un sistema tributario justo. 
COMPETENCIAS LEGISLATIVAS DEL ESTADO Y DE LAS COMUNIDADES AUTÓNOMAS...

\section{Reserva de ley: principios y finalidades}

Ya sabíamos que la reserva de ley es una de las instituciones centrales del Estado de Derecho, al representar la voluntad popular, garantizar la separación de poderes, sustentar la libertad personal y patrimonial, y posibilitar el ejercicio real de los derechos fundamentales. Para esta doctrina del TC, la reserva de ley en materia tributaria está al servicio de otros fines: sólo la Ley del Estado puede garantizar el establecimiento de un sistema tributario justo, inspirado en los principios de igualdad, progresividad y generalidad (artículo $31 \mathrm{CE}$ ), que además sirva a los objetivos de política económica general y de equilibrio entre todos los territorios. Como sabemos, el Constituyente excluyó de la sección primera del capítulo I del Título I CE, artículos 15 a 29, el derecho fiscal, pero la definición de este derecho en términos de generalidad, igualdad y justicia, permiten su identificación con los valores que establece el artículo 14 (igualdad), el 9 (promoción de la igualdad por los poderes públicos) y el propio preámbulo de la Constitución. Como si de una transacción entre los constituyentes se tratara, la reserva de ley en materia fiscal se reguló fuera del ámbito de los derechos fundamentales y de las libertades públicas, pero como su proximidad indica ${ }^{13}$ su aplicación tiene que realizarse de acuerdo con los derechos fundamentales por constituir una mera aplicación del principio de igualdad.

El sistema tributario está presidido por el principio de igualdad de todos ante la ley que establece el artículo $14 \mathrm{CE}$. Lo que quiere decir - aunque no se exprese directamente en los fundamentos de la Sentencia- que existe una relación directa entre el derecho básico y fundamental a la igualdad - superprotegido en el artículo 14 del Título I CE- y el establecimiento de los tributos, que no pueden quedar a la libre decisión municipal y/o a las regulaciones distintas y aún opuestas de las Comunidades Autónomas, que vendrían a menoscabar, añade la Sentencia, la posición de paridad que ocupan (tienen derecho a ocupar) todos los ciudadanos.

No aclara el TC qué entiende por «preservar la posición de paridad básica de todos los ciudadanos», pero sin duda está directamente relacionada con garantizar y mantener la unidad del ordenamiento, y sólo puede hacer referencia al establecimiento de un sistema tributario único en todo el Estado que, al mismo tiempo que expresa esta unidad del ordenamiento, cumple con las exigencias del derecho a la igualdad en derechos y obligaciones de todos los ciudadanos, proscribiendo la discriminación. Es más, esta unidad del ordenamiento también está puesta al servicio de los ciudadanos y de la consecución de distintos fines constitucionalmente relevantes: ser instrumento de los objetivos de una política fiscal y económica, servir para establecer un sistema tributario justo, y cumplir con los objetivos de solidaridad territorial que sólo el Estado puede garantizar.

\footnotetext{
${ }^{13}$ Curiosamente, el artículo $31 \mathrm{CE}$ es el inmediato siguiente a los derechos fundamentales y de las libertades públicas que gozan de las protección reforzada de los artículos 53.2 y $81 \mathrm{CE}$.
} 
Por esta vía y por su directa especial relación con los principios constitucionales establecidos en los artículos 131, 133 y 138 CE, también y con mayor importancia con los artículos 9 y $14 \mathrm{CE}$, el TC va a entender que los principios de igualdad, generalidad y capacidad económica que presiden en el artículo $31 \mathrm{CE}$ la regulación del principio de reserva de Ley en materia tributaria son una manifestación del derecho a la igualdad que informa, desde el mismo preámbulo, toda la Constitución Española de 1.978, y desde su regulación en el artículo 14 preside todo el capítulo 2 del Titulo I, y en especial el sistema de protección jurisdiccional y constitucional -recurso especial en materia de derechos fundamentales y recurso de amparo, respectivamente- - El derecho a la igualdad tendrá así un ámbito tributario que podrá justificar una protección judicial en vía de recurso administrativo y constitucional ${ }^{14}$, al mismo tiempo que en un efecto reflejo, servirá de título competencial al Estado para argüir y fundamentar sobre su competencia exclusiva y excluyente en la materia ${ }^{15}$.

\section{Necesidad de previa regulación por Ley del Estado}

El ámbito de la reserva de ley no puede utilizarse para desapoderar a los municipios de cualquier intervención en la ordenación del tributo o en su exigencia, tampoco podrá el legislador abdicar de toda regulación directa en el ámbito parcial que así le reserva la Constitución (art. 133,1 y 2), le corresponde a la Ley del Estado la creación ex novo de cada figura tributaria y la determinación de su contenido esencial. Las Corporaciones Locales podrán exigir tributos de acuerdo con la Constitución y de conformidad con lo dispuesto en las Leyes. El legislador no pude desconocer al regular el sistema tributario local las exigencias de la reserva de Ley, y no puede limitarse a una mera mediación formal, en cuya virtud se apodere a las Corporaciones Locales para conformar, sin predeterminación alguna, el tributo de que se trate ${ }^{16}$.

${ }^{14}$ STC 19/87 Fto Jco. 3 «...Estos preceptos, el 14 y el 31, como algunos otros que podrían citarse (v.gr. el 9.2) son reflejo del valor superior consagrado en el art. 1, pero no tienen todos ellos el mismo alcance, ni poseen la misma eficacia».

${ }^{15}$ STC 19/87 Fto. Jco. 4. «... Esta garantía de la autodisposición de la comunidad sobre sí misma, que en la Ley estatal se cifra (art. 133.1), es también, en nuestro Estado constitucional democrático, como hemos puesto de relieve más arriba, una consecuencia de la igualdad y por ello preservación de la paridad básica de posición de todos los ciudadanos, con relevancia no menor, de la unidad misma del ordenamiento (art. 2 de la Constitución), unidad que —en lo que se refiere a la ordenación de los tributos y, de modo muy especial, de los impuestos-entraña la común prosecución, a través de las determinaciones que la Ley contenga, de objetivos de política social y económica en el marco del sistema tributario justo (art. 31.1) y de la solidaridad (art. 138.1) que la Constitución propugna».

${ }_{16}$ STC 19/87 Fto Jco. $4^{\circ} 4$ in fine: «... Las Leyes reclamadas por la Constitución en este último precepto no son, por lo que a las Corporaciones Locales se refiere, meramente habilitadoras para el ejercicio de una potestad tributaria que originariamente sólo corresponde al Estado. Son también Leyes ordenadoras -siquiera de modo parcial, en mérito de la autonomía de los municipios- de los tributos así calificados de «locales», porque la Constitución encomienda aquí al legislador no sólo el reconocer un ámbito de autonomía al ente territorial, sino también garantizar la reserva legal que ella misma establece (art. 31.3), y cuyo sentido hemos recordado con anterioridad.» 
COMPETENCIAS LEGISLATIVAS DEL ESTADO Y DE LAS COMUNIDADES AUTÓNOMAS...

\section{Imposibilidad de cláusulas habilitadoras}

El ámbito de la reserva de ley no queda cubierto en materia de haciendas territoriales por el establecimiento de cláusulas meramente habilitantes que den cobertura a una regulación por completo autónoma de los Ayuntamientos en materia fiscal ${ }^{17}$. El principio democrático que rige en la $\mathbf{C E}$ para la constitución de los Ayuntamientos (art. 140 de la Constitución) es el que real y definitivamente fundamenta el poder de autodisposición en el establecimiento de los deberes tributarios. Este poder representativo configura la naturaleza esencialmente política de la autonomía municipal y no sólo administrativa -si sólo tuviera este carácter y naturaleza no podría cumplir con las exigencias democráticas del principio de reserva de Ley en materia tributaria y no tendría posibilidad de intervenir en la regulación de sus tributos- pero nunca podrá colmar todos los requisitos y las exigencias de la reserva de Ley que, en materia fiscal, está también al servicio de otros principios y finalidades constitucionales.

\section{Necesaria predeterminación y encuadramiento por Ley del Estado del Poder Tributario local}

El concepto constitucional de la reserva de ley exige la previa determinación por una ley del Estado de los elementos esenciales del tributo local: la determinación de los elementos esenciales del tributo corresponde necesariamente a la Ley del Estado. Sin perjuicio de que la propia naturaleza del Estado Español de $1978^{18}$ y del principio de Autonomía Territorial que le informa obliga al legislador, en materia de tributos locales, a reconocer a las Corporaciones Locales una intervención en el establecimiento o en la exigencia de aquéllos. El detalle de la ley del Estado será máximo a la hora de definir el hecho imponible - verdadero núcleo duro de la reserva de ley en materia tributaria, que permanecerá indisponible al Poder Local de ordenanza fiscal一.

En el resto de los elementos esenciales del Tributo, como la definición de la base imponible y del tipo, en cuanto elementos necesarios para la determinación del importe de la cuota tributaria - también la base imponible es un elemento esencial del tributo-, el grado de determinación de la Ley del Estado será mayor o menor según se trate de impuestos o de otras prestaciones de naturaleza pública — tasas, contribuciones especiales—, que tienen mayor presencia de la voluntad particular y pueden permitirse una regulación local más completa y compleja a la hora de definir bases y tipos dentro de los cri-

\footnotetext{
17 Conclusión que, en estos términos absolutos, sería incluso inexacta respecto de entes dotados de potestad legislativa, como son las Comunidades Autónomas (arts. 149.1-1. ․, 156.1 y 157.3 de la Constitución).

${ }^{18}$ STC 32/81. Concepto de Autonomía Territorial.
} 
terios generales establecidos por la ley del Estado ${ }^{19}$. Esta mayor libertad de configuración local será imposible en materia de impuestos que, para esta doctrina constitucional, requieren la previa definición por ley del Estado de todos sus elementos esenciales, con predeterminación total y completa del ámbito normativo que se reserva a las Corporaciones Locales. Se opta así por la fórmula del previo establecimiento por el Estado de diversas escalas, en materia de bases y tipos impositivos, que serán progresivas en correspondencia con el criterio de la población, fundamentalmente. El legislador estatal está obligado a una regulación parcial de los tipos del impuesto, predisponiendo criterios o límites para su ulterior definición por cada Corporación Local, a la que corresponderá ya, en el ejercicio de su autonomía y en atención a las peculiaridades de su hacienda propia, la precisión de cuál sea el tipo que, de acuerdo con el marco legal, haya de ser aplicado en su respectivo ámbito territorial ${ }^{20}$.

\section{TITULOS COMPETENCIALES DE LAS COMUNIDADES AUTONOMAS EN MATERIA DE TRIBUTOS LOCALES (SISTEMA TRIBUTARIO)}

\section{Vaciado de competencias}

Las Comunidades Autónomas Históricas verán en el proyecto de la Ley reguladora de las Haciendas Locales un atentado al sistema de distribución de competencias establecido en los artículos 148 y 149 de la CE, por el que normalmente les correspondería una legislación de desarrollo de las «Bases» establecidas por el Estado en materia tributaria y financiera de las Corporaciones Locales, que luego el Proyecto de ley les niega. La Ley 39/88, reguladora de las Haciendas Locales, se dicta prescindiendo casi enteramente de las competencias que las Comunidades Autónomas han asumido en la materia. Desde su Preámbulo, se afirma su aplicación integral, uniforme y completa en todo el territorio nacional, sin reconocer posibilidad de desarrollo normativo alguno por parte de las Comunidades Autónomas en la materia. Esta competencia exclusiva y excluyente será objeto de varios recursos de

\footnotetext{
19 STC núm. 221/1992 (Pleno), de 11 diciembre Alcance de la reserva de Ley según lo distintos elementos del tributo.

${ }^{20}$ STC 19/87, Fto. Jco. 4ºúlitmo párrafo: «...Siempre será posible una intervención municipal, que habrá de ser encauzada por la previa regulación del Estado. El legislador no puede renunciar al establecimiento de limitaciones en el ejercicio de la potestad tributaria de las Corporaciones Locales. La renuncia plena por la Ley a todo encuadramiento normativo de la potestad tributaria local no se acomoda, en definitiva, con lo dispuesto en el art. 133.2 de la Constitución ni con la general reserva de Ley establecida en este ámbito por el art. 31.3 de la Norma fundamental, pues esta reserva — como hemos indicado- está también al servicio de la procuración del «sistema» tributario al que se refiere el apartado primero del precepto constitucional citado y de la igualdad de los ciudadanos dentro de él y no se compadece, por ello, con habilitaciones indeterminadas para la configuración de los elementos esenciales de los tributos.»
} 
inconstitucionalidad que se verán resueltos por la STC 233/1999, de indudable interés para desentrañar la evolución de la doctrina constitucional en la materia, para conocer y para valorar el verdadero contenido y alcance de los distintos títulos competenciales esgrimidos por el Estado y por las Comunidades Autónomas en materia de Hacienda Local.

El artículo 1 de la Ley 39/88 establece varios tipos de reserva, según se trate de establecer el régimen jurídico financiero de la Administración Local (artículo 149.1.18 CE), definir y establecer su sistema tributario (artículo $133 \mathrm{CE}$ ) o regular su participación en los tributos del Estado (artículo 142 $\mathrm{CE}$ ), para terminar con un sin perjuicio de las competencias exclusivas del Estado (artículo 149.1.14. CE) en materia de Hacienda General. La regulación es tan completa y detallada que imposibilita y ahoga cualquier desarrollo posterior por parte de las Comunidades autónomas que hubieran asumido - o puedan asumir - competencias en la materia. Tan sólo se admite la intervención autonómica en alguna función residual o de pura ejecución material. Desde este punto de vista, puede hablarse de una frustración cierta de las expectativas de las Comunidades Autónomas Históricas.

\section{Concepto unitario de la materia Régimen Local}

Para las tesis favorables a las competencias legislativas de las CCAA en materia tributaria local, esta fundamentación separada y autónoma de las competencias legislativas del Estado en materia de Haciendas Locales se opone y contradice el concepto unitario que debe presidir la materia Régimen Local, tal como ha sido definida por el TC desde la célebre Sentencia de 2 de febrero de 1981. Concepto unitario luego afianzado por la Sentencia de 5 de diciembre de 1984, cuyo fundamento jurídico $3^{\circ}$, admite la sustantividad del ámbito material comprendido en la expresión «Régimen Local». Este concepto unitario y básico del Régimen Local está conceptualmente opuesto a la decisión del Legislador Estatal de establecer una legislación «de Bases» y de «Haciendas Locales» con fundamento constitucional distinto, pero con la idéntica finalidad de eliminar por completo cualquier desarrollo legislativo por parte de las Comunidades Autónomas, que hubieran asumido o asuman en sucesivos desarrollos autonómicos y reformas de sus Estatutos de Autonomía competencias legislativas en materia de Régimen Local.

Para estas opiniones, la Hacienda Local no es una materia propia y distinta del Régimen Local, en el que obligatoriamente se integra; tampoco puede constituir de facto un título competencial a utilizar por el Estado en su propio beneficio y a los solos efectos de excluir todo desarrollo legislativo autonómico. La propia Ley reguladora de las Haciendas Locales reconoce abiertamente la existencia de un concepto unitario de régimen local. La Exposición de Motivos de la Ley justifica el retraso del desarrollo de esta ma- 
teria $^{21}$ por el concepto unitario que debe presidirla. Unidad que se confirma y ratifica en el apartado II de la misma Exposición de Motivos que reconoce expresa y abiertamente que se presenta una Ley complementaria de la LBRL, que se limitó en su Título VIII a recoger los «principios generales básicos» previstos en los arts. 137 y 142 CE. Esta unidad o complementariedad explicaría, asimismo, la referencia del artículo 1.1 de la Ley 39/88, al 149.1.18 CE para fundamentar la competencia del Estado en el establecimiento de las «bases» del régimen económico financiero de la Administración local.

\section{Alcance del concepto bases 149.1.18 CE}

El Régimen Jurídico a que se refiere el artículo 149.1.18 CE no agota todos los aspectos que pueda ofrecer la regulación de una Entidad Pública —ésta será la tesis central de los postulados de los recursos de inconstitucionalidad presentados por las Comunidades Autónomas-. La materia «Régimen Local» es más amplia que la reiterada expresión «régimen jurídico» del art. 149.1.18 CE, de tal manera que siempre quedará, y así tiene que respetarse y reconocerse, un amplio espacio para la legislación de desarrollo a cargo de las Comunidades Autónomas que hayan asumido o puedan asumir competencia exclusiva en materia de Régimen Local.

Este concepto unitario del «Régimen Local» se ha establecido directamente en el artículo $106^{22}$ de la propia Ley de Bases del Régimen Local que anuncia la existencia de un sistema tributario local propio y autónomo, de acuerdo con la Ley del Estado reguladora de las Haciendas Locales... y de las leyes de las Comunidades Autónomas en los supuestos expresamente previstos en aquella. Se reconoce y acepta la necesidad y existencia de un Sistema Tributario Local propio y autónomo - artículos 137, 140 y 142 CE-, para el que se sientan sus fuentes normativas en esta ley 39/88, también en referencia expresa al artículo 133.1 y 2 CE. Teniendo en cuenta que la Ley -Estatal o Autonómica - que establezca-desarrolle el Sistema Tributario Local tiene que respetar la existencia de un poder propio y autónomo: la Autonomía Local tiene que tener su reflejo en su sistema tributario.

El establecimiento del sistema Tributario Local implica un desarrollo directo de la Constitución, al igual y en paralelo a como lo fue el establecimiento de las Bases del Régimen Local. En los Estados compuestos y tan política-

\footnotetext{
${ }^{21}$ La Ley 7/1985 no culminó íntegramente la ordenación del sector local, por cuanto que un aspecto fundamental de este último, cual es el relativo a la actividad financiera, sólo puede ser regulado en algunos de sus aspectos más generales».

22 «Las entidades locales tendrán autonomía para establecer y exigir tributos de acuerdo con lo previsto en la legislación del Estado reguladora de las Haciendas locales y en las leyes que dicten las Comunidades Autónomas en los supuestos expresamente previstos en aquélla».
} 
COMPETENCIAS LEGISLATIVAS DEL ESTADO Y DE LAS COMUNIDADES AUTÓNOMAS...

mente descentralizados como el nuestro, que reconoce la existencia de nacionalidades, regiones, islas, territorios históricos — con reconocimiento constitucional de sus derechos-, la legislación del Estado tendrá siempre el papel principal en la definición del sistema tributario local. Sólo esta legislación puede garantizar la existencia de un verdadero sistema tributario local autónomo e inmune a futuros desarrollos por Ley de cada Comunidad Autónoma, y sólo ésta puede establecer el papel que le pueda corresponder o no a las Comunidades Autónomas en el encuadramiento final y definitivo de la autonomía financiera local. La dicción del artículo 106 de la Ley de Bases de Régimen Local vendría a ser un trasunto o aplicación del artículo 133.2 $\mathrm{CE}$, al reconocer y enmarcar esa potestad en el marco de la Constitución y las leyes, y la Ley de Bases del Régimen Local la refiere a la «legislación del Estado reguladora de las Haciendas Locales» y, de otro, que también habrá de ajustarse a las «leyes que dicten las Comunidades Autónomas en los supuestos expresamente previstos en aquélla». Queda siempre en manos del Estado la definición de los criterios, ámbito, contenido y alcance de la legislación de las Comunidades Autónomas en materia de Tributos Locales ${ }^{23}$.

La importancia de tan citado artículo 106 LBRL está en el reconocimiento expreso por Ley del Estado de una posible legislación de las Comunidades Autónomas en materia de tributos locales. Lo que no prejuzga que se trate de un imperativo constitucional ni que tal presencia sea conveniente o necesaria. Sin omitir que se trata de un texto legislativo alumbrado con antelación al dictado de las principales Sentencias del TC en la materia, circunstancia que le invalida para servir de guía y garantía contra evoluciones doctrinales contrarias a aceptar la atribución de potestades normativas a las Comunidades. La evolución legislativa y la propia doctrina del TC —con muchos matices y recovecos- ha sido y es contraria a tal reconocimiento. Esta evolución se mantiene vigente sin solución de continuidad desde la publicación de la Ley 39/88 de Haciendas Locales, pasando por todas sus modificaciones sustanciales, hasta la reciente publicación de la Ley 1/2006, de 13 de marzo, por la que se regula el Régimen Especial del municipio de Barcelona, que sigue sin reconocer ni reservar participación alguna a la Comunidad Autónoma de Cataluña en la regulación del Sistema Tributario de Barcelona: el Legislador estatal sigue entendiendo que la total regulación de la Hacienda local es competencia exclusiva del Estado.

La ley 39/1998 se aparta por completo del sistema de distribución de competencias anunciado para la regulación de las Haciendas Locales en el artí-

\footnotetext{
${ }^{23}$ María Dolores Arias Abellán, Tributos Locales núm. 31, julio de 2003, p. 14 «...De manera que tanto el Estado como las Comunidades Autónomas pueden incidir en la delimitación de las competencias relativas al poder tributario local porque el término «leyes» utilizado en el artículo 133.2 de la CE incluye, claro está, a las que dicte el Estado, en ejercicio de sus competencias, y a las que dicte la Comunidad Autónoma en el ejercicio de las suyas. Lo importante es este reconocimiento expreso respecto de las Comunidades Autónomas como entes públicos que, mediante ley, pueden ejercer competencias relativas al poder tributario local, delimitando su contenido y alcance, tal y como exige la propia Constitución».
} 
culo 106 LBRL. El artículo 1 de la LRHL excluye directamente del concepto constitucional de bases de las Administraciones Públicas todos los preceptos que regulan el sistema tributario local —dictados en virtud de lo dispuesto en el artículo 133 CE_ ... «...y los que desarrollan las participaciones en los tributos del Estado a que se refiere el artículo 142 de la Constitución todo ello sin perjuicio de las competencias exclusivas que corresponden al Estado en virtud de lo dispuesto en el artículo 149.1.14 de la Constitución.» La nueva LRHL se aparta definitivamente de una concepción unitaria del Régimen Local. La «máxima» establecida por la CE en materia de distribución de competencias entre el Estado y las Comunidades Autónomas - legislación básica del Estado/legislación de desarrollo por las Comunidades Autónomasno servirá para establecer la misma relación entre potestad originaria del Estado para establecer tributos y potestad derivada de las Comunidades Autónomas para exigirlos, de acuerdo con la Constitución y las leyes. La ley 39/88 impone un modelo distinto de distribución de competencias que, para los defensores de las competencias de las Comunidades Autónomas, amplía los títulos constitucionales del Estado y vacía de contenido las competencias estatutarias ya asumidas por determinadas Comunidades Autónomas en materia de Régimen Local.

El planteamiento monopolístico en materia de Hacienda que ya realizó el Estado con motivo de la LBRL se ha elevado hasta la negación de cualquier participación de las Comunidades Autónomas, con fundamento en nuevos títulos competenciales ${ }^{24}$. Ahora es el artículo 133.1 CE el que autoriza la competencia del Estado pueda concretar el contenido del poder tributario local. Lo que no impide, al menos teóricamente, la intervención de las Comunidades Autónomas... en la medida en que así lo establezca la ley derivada del ejercicio de esa potestad exclusiva del Estado. Sin embargo, la potestad originaria del Estado para establecer tributos no puede utilizarse para delimitar o atribuirse competencias de las que se carece ${ }^{25}$. El artículo $133.1 \mathrm{CE}$ no es ni puede utilizarse como cauce de atribución de competencias sobre Hacienda Local y el ejercicio del poder tributario no puede excluir el normal ejercicio de las competencias de las Comunidades Autónomas sobre Régimen local $^{26}$.

La diferencia de criterio no es de detalle. Para las Comunidades Autónomas, el Régimen Local es una competencia exclusiva propia. El Estado no

\footnotetext{
${ }^{24}$ El artículo 1 de la Ley 39/88 fundamenta su apoyatura competencial en los arts. 149.1.18, 149.1.14, 133 y 142 Constitución.

${ }^{25}$ Ferreiro Lapatza, «Principios Generales de la Hacienda Local y competencias de las Comunidades Autónomas», PALAU, $\mathrm{n}^{\circ} 7$.

${ }^{26}$ STC 179/1985 que «cuando, usando de su competencia en materia de Hacienda General, el Estado regula cuestiones referentes a la Administración Local, no puede desconocer la delimitación competencial que respecto de ella existe entre el propio Estado y algunas Comunidades Autónomas»; razón por la cual si ha de «introducir modificaciones en el régimen jurídico de esta Administración, deberá hacerlo de modo tal que no se imposibilite el ejercicio de la facultad comunitaria para dictar las normas de detalle».
} 
tiene el monopolio legal sobre el Régimen Local o cualquiera de sus aspectos, y su poder originario para establecer tributos tiene que ejecutarse y tramitarse dentro del concepto más amplío de las bases del régimen jurídico local (149.1.18), del que sin duda forma parte el sistema tributario, y así se ha reconocido por la Jurisprudencia Constitucional en la S 179/85 que establece una «reserva de competencia legislativa a favor de determinadas comunidades Autónomas» que tiene que ser preservada por el Estado al regular materias y cuestiones referentes a la Administración Local.

\section{TÍTULOS COMPETENCIALES DEL ESTADO}

Para las posiciones favorables al reconocimiento de competencias normativas de las Comunidades Autónomas sobre el Sistema Tributario Local, si la potestad originaria para establecer tributos no puede servir de título excluyente de la legislación de las Comunidades Autónomas en el Sistema Tributario Local, menos puede serlo el título «Hacienda General», que se esgrime en el artículo 1 de la Ley 39/88 a modo de cláusula de cierre del sistema. El propio concepto de Hacienda General carece de precisión y contenido claro, para la STC 14/1985, el concepto de Hacienda General no se identifica con el de Hacienda del Estado, sino que hace referencia a las competencias del Estado para relacionar las distintas haciendas territoriales como piezas de un conjunto con una acusada interdependencia. Competencia cuya relación con las Haciendas Locales se analizó por primera vez en la STC 179/1985: «...cuando, usando de su competencia en materia de Hacienda General, el Estado regula cuestiones referentes a la Administración Local, no puede desconocer la delimitación competencial que respecto de ella existe entre el propio Estado y algunas Comunidades Autónomas»; razón por la cual si ha de «introducir modificaciones en el régimen jurídico de esta Administración, deberá hacerlo de modo tal que no se imposibilite el ejercicio de la facultad comunitaria para dictar las normas de detalle...».

\section{Hacienda general 149.1.14 CE}

Por esta vía, como había afirmado la doctrina ${ }^{27}$, el diseño del Sistema Tributario Local es una materia compartida entre el Estado y las Comunidades Autónomas que tengan asumidas competencias exclusivas sobre régimen local en sus respectivos Estatutos. El Estado sólo podrá hacer prevalecer este título «en aquellos casos en los que la normativa estatal tenga por objeto la regulación de instituciones comunes a las distintas Haciendas o de medidas de coordinación entre la Hacienda estatal y las Haciendas de las

\footnotetext{
${ }^{27}$ Ferreiro Lapazta, J.J., «Principios Generales de Hacienda Local y competencias de las Comunidades Autónomas», Palau 14, nº 7.
} 
corporaciones locales. O también, cuando su finalidad sea la salvaguarda de la suficiencia financiera de las Haciendas Locales garantizada en el artículo $142 \mathrm{CE}$, en cuanto presupuesto indispensable para el ejercicio de la autonomía local».

En estas materias: coordinación entre las distintas Haciendas, regulación de las instituciones comunes a las distintas Haciendas - Ley General Tributaria y sus normas de desarrollo- y salvaguardia de la suficiencia financiera de los Entes Locales, de acuerdo con lo dispuesto en el artículo 142 CE - preside la regulación constitucional de la Hacienda Local y rige sus relaciones de coordinación con la Estatal—, no existe posibilidad alguna de desarrollo por parte de las Comunidades Autónomas. Las competencias de coordinación y la regulación de las instituciones comunes no pueden ser objeto de desarrollo por parte de las Comunidades Autónomas.

El diseño completo de las reglas y fórmulas concretas de coordinación, también su ejecución, corresponde al Ente superior encargado del funcionamiento del conjunto. Por esta vía, y en cuanto se trate de coordinar o regular instituciones comunes, el artículo 149.1.14 CE es un título de atribución de competencia exclusiva a favor del Estado por completo distinto del concepto de Bases de las Administraciones Públicas a que se refiere el tan citado 149.1.18 CE. Lo que no quiere decir suficiente para atribuir competencia exclusiva al Estado sobre las Hacienda Local. En este sentido y con este alcance deben entenderse los razonamientos del TC en citada Sentencia 179/ 85, sobre la improcedencia de utilizar este título (Hacienda General, artículo 149.1.14) para atribuir al Estado competencia exclusiva sobre la Hacienda Local. Sin perjuicio del juego de otros títulos competenciales del Estado o del poder normativo que otros principios constitucionales básicos puedan otorgarle directamente al Estado, y venga a excluir toda competencia normativa de las Comunidades Autónomas sobre Haciendas Locales.

El artículo $142 \mathrm{CE}$, aunque desde luego tampoco es un título de distribución de competencias, como al final ha entendido la más reciente jurisprudencia constitucional SSTC 104/2000, de 13 de abril, y 48/2004, de 25 de marzo, se enmarca en la competencia de Hacienda General que atribuye al Estado el artículo 149 CE, y sitúa al Estado en posición de garante de la suficiencia del sistema de financiación de las haciendas locales. Posición que, por la fuerza de los hechos, constituye un título más a su favor en la regulación del sistema tributario local, que excluye cualquier desarrollo independiente del sistema tributario local por las Comunidades Autónomas ${ }^{28}$.

\footnotetext{
${ }^{28}$ STC 48/2004: «...Por otro lado, conviene también subrayar que, sin perjuicio de la contribución que las Comunidades Autónomas pueden tener en la financiación de las haciendas locales (éstas, en virtud del art. 142 CE, se nutrirán también de la participación en tributos de las Comunidades Autónomas), conforme hemos venido señalando reiteradamente, es al Estado, a tenor de la competencia exclusiva que en materia de hacienda general le otorga el art. 149.1.14 $\mathrm{CE}$, a quien, a través de la actividad legislativa y en el marco de las disponibilidades presupuestarias, incumbe en última instancia hacer efectivo el principio de suficiencia financiera de las haciendas locales [SSTC 179/1985,
} 
COMPETENCIAS LEGISLATIVAS DEL ESTADO Y DE LAS COMUNIDADES AUTÓNOMAS...

Puede apreciarse así una especial relación entre la competencia del Estado en materia de Hacienda General y la obligación constitucional que le impone el artículo $142 \mathrm{CE}$ para dotar de suficiencia de medios a las Haciendas Locales. La legislación del Estado que establezca y regule las relaciones de coordinación, la regulación de las instituciones comunes y la salvaguardia de todo el sistema tributario público del Estado Español con sus tres niveles de decisión -Estatal, Autonómico y Local— está mediatizada por el principio de suficiencia de las Haciendas Locales. Este mandato constitucional no sólo obliga al legislador estatal a procurar la suficiencia de medios financieros —quedando a su libre elección el sistema concreto de financiación-, le impone la existencia de un sistema tributario local propio — que sólo puede ser autónomo- - y una participación en los propios ingresos del Estado.

La Constitución de 1978 garantiza no sólo la existencia de un Sistema Tributario Local propio sino que dé cumplimiento al principio de Suficiencia. Esta garantía queda en manos del Estado como único responsable posible del establecimiento de las instituciones comunes de las distintas Haciendas, y de un nivel equivalente de ingresos entre los Ayuntamientos de todas las Comunidades Autónomas. El concepto constitucional de Hacienda General alcanza aquí al establecimiento de los elementos fundamentales del sistema tributario local que, por imperativo constitucional, tienen que ser comunes a todos los Ayuntamientos. No puede asumirse la existencia de múltiples y aún opuestos sistemas tributarios locales, al albur de las distintas iniciativas de las Comunidades Autónomas. Por el contrario, la garantía del establecimiento de un Sistema Tributario Local igual y suficiente forma parte del concepto de Hacienda General, que sirve para definir los criterios básicos de la financiación de las Haciendas Locales de aplicación uniforme en todo el Estado.

En resumen, la ya declarada interacción entre estos títulos competenciales del Estado - Hacienda General y Suficiencia Financiera - y su posición de garante de la suficiencia del sistema tributario local, implica una atribución de competencia en la regulación del Sistema Tributario Local que va más allá de la relación legislativa «patrón» que establece la Constitución entre el Estado y las Comunidades Autónomas en términos formales de «bases» regulación por el Estado sólo de los aspectos esenciales de una institución, «legislación de desarrollo»—normación de detalle por la comunidad autónoma de la misma institución, de acuerdo con lo criterios básicos establecidos por el Estado- y siempre que hubieran asumido competencias legislativas en sus propios Estatutos de Autonomía ${ }^{29}$.

de 19 de diciembre (RTC 1985; 179), F.3; 96/1990, de 24 de mayo (RTC 1990/96), F.7; 237/1992, de 15 de diciembre (RTC 1992/237), F.6; 331/1993, de 12 de noviembre (RTC 1993/331), F.2 b); 171/ 1996, de 30 de octubre (RTC 1996,171), F.5; 233/1999, de 16 de diciembre (RTC 1999, 233), FF. 22; 104/2000, de 13 de abril (RTC 2000,104), F.4].

${ }^{29}$ «...El legislador estatal no sólo distribuye y delimita las materias imponibles, sino que puede también crear las figuras tributarias «más adecuadas para el mejor y más racional aprovechamiento de una materia imponible»; debiendo notarse a este respecto que la diferencia entre «materia imponible» $y$ «hecho imponible» ha sido asumida en la STC 37/1987 (fundamento jurídico $14^{\circ}$ )». 
Es posible que estos nuevos «títulos» competenciales del Estado no agoten la materia y, como sostiene una parte de la doctrina ${ }^{30}$, no excluyan el ulterior desarrollo de esa regulación a favor de las Comunidades Autónomas, al igual que la atribución del poder tributario originario al Estado no debe suprimir la potestad tributaria de los Entes Locales y de las Comunidades Autónomas, aunque pueda condicionarla. El Estado podrá elegir las bases que quiera, condicionar, coordinar y reservar quizá un papel menor de lo habitual para el desarrollo a efectuar por las Comunidades Autónomas, pero con estos títulos no puede excluir por completo la competencia de las Comunidades. Puede, en definitiva, el Estado aplicar también los poderes y facultades que le atribuye el art. 149.1.14 de la CE, y la posición de garante del sistema tributario, pero sin otros títulos, justificaciones o principios constitucionales, no puede excluirse ni relegarse por completo el poder normativo ya asumido por las Comunidades Autónomas en sus respectivos Estatutos.

\section{Relación Especial entre el artículo 133.2 CE y el artículo 149.1.14 CE}

Puede aceptarse la crítica de una parte de la doctrina que entiende que el art. 133.1 CE no es una norma de distribución competencial —establece una reserva de ley-, sin embargo, como sucede con otras normas constitucionales —art. 133.2 $\mathrm{CE}{ }^{31}$, presupone la competencia estatal para establecer todos los tributos. En el establecimiento y regulación de los tributos estará presente también la competencia sobre Hacienda general (art. 149.1.14 CE), que constituye la justificación normal en todos los supuestos de ejercicio del poder tributario del Estado, con independencia del «nivel de Hacienda» y del sistema o subsistema tributario que afecten ${ }^{32}$. En el mismo sentido, la STC 181/1988, Fto. Jco $3^{\circ}$, establece una relación directa y precisa entre los recursos de las Comunidades Autónomas (art. 157.3 CE) y la competencia originaria (artículo 133.1 CE) del Estado para establecer tributos y con el 149.1.14. En definitiva, la competencia exclusiva del Estado sobre la Hacienda general se extiende y abarca a la regulación de todos los elementos comunes de las Haciendas Territoriales, a la coordinación entre todas ellas,

\footnotetext{
${ }^{30}$ María Dolores ARIAS Abellán, «Las Competencias Autonómicas para cofigurar el sistema tributario de los Entes Locales». Tributos Locales, $\mathrm{n}^{\circ}$ 31, julio de 2003, p. 17: Si la competencia estatal para llevar a cabo esta labor es el articulo 149.1.14, parece evidente que su ejercicio no puede desconocer la distribución de competencias en hacienda local dentro de la que también debe incluirse la materia tributaria. De manera que al amparo de ese titulo competencial no puede agotarse todo el régimen jurídico del sistema tributario local porque eso sería desapoderar, sin base constitucional, a esas Comunidades Autónomas y eso sin perjuicio de las medidas concretas que deban adoptarse por el Estado ex articulo 149.1.14 cuando la coordinación, las relaciones entre Hacienda estatal y Hacienda local, así lo exigen.

${ }^{31}$ STC 227/1988, fundamento jurídico $14^{\circ}$.

${ }^{32}$ Quintana Ferrez, E., «Incidencia de la Hacienda General en la Hacienda Autonómica», RDFHP, $n^{\circ} 243$
} 
y a la selección de sus respectivas materias y hechos imponibles (STC 14/ 1986) ${ }^{33}$, y alcanza también a la regulación del sistema tributario $\operatorname{local}^{34}$, y a la competencia para regular el sistema tributario y financiero de las Comunidades Autónomas, de acuerdo con la reserva de Ley que incorpora el art. 157.3 CE.

El Estado, en uso de esta competencia sobre Hacienda General, está obligado a establecer los elementos comunes de las instituciones básicas del derecho tributario, que serán compartidas por todas las Haciendas territoriales. También a la atribución o selección de la materia imponible para cada nivel de Hacienda, y a la elección de las figuras tributarias concretas del Régimen Local, y con menor detalle del sistema tributario de las Comunidades Autónomas que, más que tributos propios, han terminado por configurar un complejo sistema de participación en los tributos del Estado, y una imposición ambiental, que tiene carácter finalista. Las competencias del Estado en materia de Hacienda General y la originaria para establecer tributos se relacionan y complementan, y están presididas por el principio de legalidad. Le corresponde al Estado, por imperativo de la reserva de ley tributaria, establecer los elementos esenciales del tributo y encuadrar las facultades de las Corporaciones Locales, y por la misma reserva y por el mandato constitucional expreso, artículo 157.3, coordinar el ejercicio de las competencias financieras de las Comunidades Autónomas.

\section{Poderes normativos y de ordenación que atribuye al Estado el artículo 133.1 CE}

El Poder Constituyente de 1978 reservó exclusivamente al Estado (artículo 133.1 CE) el poder originario poder para establecer tributos, dentro de

\footnotetext{
${ }^{33}$ CheCA GonZÁlez: «No se aprecia que pueda conculcarse, ni aun erosionarse en lo más mínimo la competencia de naturaleza tributaria de las Corporaciones Locales por el simple hecho de que la Comunidad Autónoma en las que las mismas estén territorialmente incardinadas decida implantar un impuesto propio que para nada perturbe, ni incida en forma alguna, en el poder tributario local, esto es, un impuesto regional que no venga a atentar contra la capacidad recaudatoria de las Entidades Locales, sino que funcione independientemente, y al margen, de cualquiera de las figuras impositivas locales, que continúan subsistiendo, pese a que tenga relación con las materias tributarias "propias"... de éstas». Así esto, si se estableciese que el art. 6.3 LOFCA realiza un reenvío en blanco a la Ley de Haciendas Locales, en cuanto a la materia reservada a estas se refiere, en tanto que según la misma sentencia del Tribunal Constitucional 137/1986 «cabría reputarse ilegítimo todo reenvío en blanco o con condiciones tan laxas que viniesen a defraudar la reserva constitucional a favor de la Ley Orgánica», sería válido señalar la posible inconstitucionalidad del art. 6.36 LOFCA con lo cual, el problema no se ve resuelto, sino agudizado. No podemos compartir la segunda de las premisas. La irrelevancia recaudatoria de cualquier impuesto con fines extrafiscales nada tiene que ver con la prohibición constitucional de invadir materia imponible reservada a las Corporaciones Locales, materia, por otra parte, reseñada claramente en la Ley de Haciendas Locales sin que ello signifique que se producto de una remisión en blanco de la LOFCA hacia aquélla. Vid. Checa González, C., Los impuestos propios de las Comunidades Autónomas. Ensayo de superación de las fuertes limitaciones existentes para su implantación, Aranzadi, Pamplona, 2002, pp. 94 ss.
}

${ }^{34}$ STC $19 / 1987$, fundamentos jurídicos $4^{\circ}$ y $5^{\circ}$. 
una determinada estructura territorial del poder, expresamente aludida en el art. 133.2 CE. Esta atribución del poder originario para establecer tributos tiene un significado claro y evidente: es el quicio del reparto constitucional de la potestad tributaria entre los diversos niveles de Hacienda: estatal, autonómico, local. Para el TC -Fto. Jco. 22 S 233/99 - cuando se trata de establecer el sistema tributario local, las exigencias de la reserva de Ley ${ }^{35}$ que se expresan en el artículo $31 \mathrm{CE}$, sólo pueden cumplirse por la Ley del Estado, por imponerlo así los números 1 y 2 del artículo $133 \mathrm{CE}$. Son pues los contenidos y exigencias de la reserva de Ley (generalidad e igualdad), que no se citan en la doctrina del TC - habla de garantizar una básica igualdad de posición de todos los ciudadanos y de preservar la unidad del ordenamiento-, los que a la postre, por su relación directa con el ya comentado título sobre Hacienda General y con el principio de suficiencia financiera local, reclaman la intervención necesaria e inexcusable de la Ley del Estado, que puede negar la intervención de las Comunidades Autónomas en este concreto ámbito normativo ${ }^{36}$. A pesar de opiniones en contra como la del profesor Ferreiro Lapatza, para quién «el poder originario del Estado significa, pues, en la Constitución de 1978, un poder tributario condicionado sólo por la Constitución, pero condicionado también por ella. Condicionado también, en consecuencia, por el reparto de competencias que en ella se hace ${ }^{37} \gg$.

\section{Reserva de ley en materia tributaria y principio de igualdad en la CE de 1978}

El principio de reserva de Ley no sólo está al servicio de las relaciones entre poderes del Estado, para cumplir la garantía de la «autoimposición». Está en el propio origen y evolución del Estado Liberal y del Estado Democrático de Derecho. La garantía de la aprobación de la imposición por una representación democrática no es ni puede ser una garantía meramente formal, ni puede agotarse en sí misma ${ }^{38}$. Está constituida desde su origen, y así

${ }^{35} \mathrm{SSTC} 37 / 81 \mathrm{FJ}^{\circ}$, 6/83, FJ 4º $179 / 85, \mathrm{FJ} 3^{\circ}, 19 / 87 \mathrm{FJ} 4,14 / 98 \mathrm{FJ} 11$.

${ }^{36}$ STC 19/87: «La misma «existe también al servicio de otros principios —la preservación de la unidad del ordenamiento y de una básica igualdad de posición de los contribuyentes-, principios que sólo puede satisfacer la ley del Estado. Además, y desde el momento en que esta concreta potestad normativa del Estado tiene como inmediata finalidad garantizar la suficiencia financiera de tales Corporaciones - suficiencia financiera que, según indicamos ya en el fundamento jurídico $2^{\circ}$, es en última instancia responsabilidad de aquél一, su ejercicio encuentra anclaje constitucional en la competencia exclusiva sobre Hacienda General (art. 149.1.14 CE), debiendo entenderse vedada, por ello, la intervención de las Comunidades Autónomas en este concreto ámbito normativo. Todo ello no es óbice, sin embargo, para que éstas, al igual que el Estado (233/99, FJ 22).

${ }^{37}$ Ferreiro Lapatza, J.J., «La Hacienda Local. Antecedentes históricos y situación actual. El marco constitucional», Tratado de Derecho Financiero y Tributario Local, Marcial Pons, Madrid, 1993, p. 38.

${ }^{38}$ Las distintas fórmulas que pretenden otorgar contenido material a la prohibición de arbitrariedad como consecuencia del principio de igualdad suelen ser duramente criticadas por la doctrina. Desde la «naturaleza de la cosa», la «común conciencia jurídica» o «el criterio de los hombres que razonen jus- 
figura en el artículo 31 de nuestra Constitución, al servicio de los postulados proclamados por la Ilustración que arrumbaron con el Estado Absoluto y con el Despotismo Ilustrado para establecer el Estado Liberal y hacer efectivos los principios de seguridad, igualdad y libertad.

El mencionado artículo $31 \mathrm{CE}$ - todos contribuirán al sostenimiento de los gastos público, de acuerdo con su capacidad económica, mediante un sistema tributario justo, inspirado en los principios de igualdad y progresividadrecibe y aplica en materia de reserva de Ley fiscal el Principio de Igualdad que, desde su asiento en el artículo $14 \mathrm{CE}$, preside todo el capítulo II «Derechos y Libertades» de nuestra Constitución, y de forma expresa le aplica los mismos principios que rigen toda la parte dogmática de nuestra constitución, al mismo tiempo que la propia «vis» atractiva del principio de igualdad posibilita el reconocimiento y la aplicación efectiva de los recursos judiciales especiales establecidos directamente por la Constitución en los artículos 53. 2, y 161. 2, en materia de derechos fundamentales y, ante el mismo TC, en amparo de los derechos fundamentales ${ }^{39}$.

Los mandatos de generalidad e igualdad que proclama el artículo $31 \mathrm{CE}$, aunque reglados fuera de los derechos fundamentales que confieren el acceso a los recursos especiales y de amparo, «todos están obligados al sostenimiento de los gastos públicos, mediante un sistema tributario igual...» puede afirmarse aplican los mismos principios y cánones a favor del principio de igualdad y de no discriminación que resultan aplicables desde el artículo 14 al resto de los derechos fundamentales — artículos 15 a 29 y 30 CE-, y también que estos mandatos (generalidad, igualdad y capacidad económica que prescribe el artículo $31 \mathrm{CE}$ ) son un mero trasunto de la prohibición de cualquier tipo de discriminación que preside nuestra Constitución. Enlaza así el principio de legalidad en materia fiscal con el propio preámbulo de la Constitución de 1978, y con lo dispuesto en el artículo 1 CE en materia de soberanía. Como lo demuestra la aceptación a trámite de recursos de amparo y

ta y sensatamente» (LEIBHOLZ, TRIEPEL) las diversas objeciones a la interdicción de la arbitrariedad suelen fallar en la idea que sugiere TIPKE, es decir, el tratamiento igual o desigual requiere elegir la medida, el tertium comparationis que resulte relevante para la materia específica que haya de ser objeto de regulación, criterio que no es ofrecido por la fórmula de la interdicción de arbitrariedad. En este contexto, una de las más acerbas críticas es la de FRIAUF, la que ironiza al respecto calificando la interdicción de arbitrariedad como «teoría de las peras y las manzanas» cuyo contenido esencial respondería a la idea de que «las manzanas no son peras; por consiguiente, pueden recibir otro tratamiento y tributar de otro modo». Vid., por todos, el trabajo de Herrera Molina, P., Capacidad económica y sistema fiscal. Análisis del ordenamiento español a la luz del Derecho alemán (Prólogo del Prof. Klaus Tipke), Marcial Pons, Madrid, 1998, pp. 26 ss.

\footnotetext{
${ }^{39}$ Herrera Molina, P., Capacidad económica y sistema fiscal. Análisis del ordenamiento español a la luz del Derecho alemán, Marcial Pons, Madrid, 1998, pp. 32 y 33. «...Aun cuando quepa discrepar acerca de la naterualeza iusfundamental de la capacidad contributiva, lo que no es controvertible es que el ámbito material de protección del principio de proporcionalidad como un medio de concreción de los derechos fundamentales, pero no puede argumentarse sobre la protección que el principio ejerce sobre las demás disposiciones constitucionales, o sobre disposiciones amparadas por éstas. La naturaleza de cuerpo ordenado y sistemático hace necesario la ampliación del ámbito de los cánones de proporcionalidad e impide que se excluya de su examen situaciones o disposiciones ajenas al cuerpo iusfundamental...».
} 
de protección de los derechos fundamentales en materia tributaria, fundados en la infracción de los valores superiores del ordenamiento jurídico: libertad, igualdad y no discriminación, que presiden la legislación de los derechos fundamentales de los ciudadanos, reservada a ley orgánica del Estado en el artículo $81 \mathrm{CE}$, y, por lo mismo, la legislación sobre su contribución - fiscal - al sostenimiento de los gastos comunes. Quedando sujetas por igual a los mismos cánones de control constitucional que aplica el TC a la interdicción de la discriminación y al principio de proporcionalidad ${ }^{40}$.

\section{EVOLUCIÓN DE LA DOCTRINA DEL TC}

\section{Unidad del título competencial Régimen Local}

En una larga evolución el TC va a cambiar su doctrina sobre las competencias constitucionales de las Comunidades Autónomas en la definición y «encuadramiento» del sistema tributario local. Pasará desde el reconocimiento de una competencia compartida «al uso» entre el Estado y las Comunidades Autónomas - fundada en el artículo 149.1.18 CE—, a excluir cualquier tipo de competencia normativa de las Comunidades Autónomas en materia de legislación sobre el Sistema Tributario Local. En la primera decisión de importancia sobre el alcance de la Autonomía financiera Local y, en particular, sobre la distribución de competencias legislativas en el Sistema Tributario Local, la STC 179/1985, como sabemos, no establece diferencias entre los fundamentos constitucionales del Régimen Jurídico de la Administración Local y su Sistema Fiscal: «...puede afirmarse sin dificultad la naturaleza compartida de las competencias que, en materia de Haciendas locales, poseen el Estado y aquellas Comunidades Autónomas que, como la catalana, han asumido en sus respectivos Estatutos facultades en orden al desarrollo de las bases estatales sobre el régimen jurídico de las Administraciones Públicas «ex»art. 149.1.18 CE, precepto que ha de considerarse el título habilitante del Estado para ejercitar sus competencias sobre dicha materia cuando su regulación suponga introducir modificaciones de alcance general en el régimen jurídico de la Administración Local o se dicte

\footnotetext{
${ }^{40}$ Reynaldo Balladares Saballos, «Propuesta de Aplicación del Principio de Igualdad», Tributos Locales, $\mathrm{n}^{\circ}$ 48, Febrero 2005: «...El principio de proporcionalidad constituye una nota más añadida al control de constitucionalidad en términos de igualdad para la protección del contenido básico de los derechos fundamentales. Es un instrumento válido para frenar aquellas incursiones del ámbito público en materia iusfundamental que ampara, en este caso, a los contribuyentes. Como principio instrumental que es, constituye una herramienta eficaz para impedir que aquellas medidas que el Estado invoque para realizar los postulados de la igualdad material de derecho, en el marco del Estado social, conculquen derechos fundamentales de los destinatarios de tales medidas. Por ello, la doctrina jurisprudencial ha decidido añadirlo como la nota más característica del contenido de la igualdad a través de la STC 76/1990, FJ $9^{\circ}$ A anteriormente mencionada. Más adelante, mediante STC 65/1995 se establecen los criterios que estructuran al principio incardinándose de esta forma como un medio para el control constitucional de medidas sujetas al examen del Tribunal desde las posturas sostenidas, principalmente, por la doctrina iuspublicista germánica», p. 15.
} 
COMPETENCIAS LEGISLATIVAS DEL ESTADO Y DE LAS COMUNIDADES AUTÓNOMAS...

\section{en garantía de la autonomía que ésta tiene constitucionalmente garan- tizada...»}

En suma, la Hacienda Local es una parte más del Régimen Jurídico de la Administración Local. La distribución de competencias legislativas entre el Estado y las Comunidades Autónomas que hubieran asumido competencias en Régimen Local —ahora, con la tramitación de nuevos Estatutos de Autonomía, parece que todas - no ofrece diferencias en materia fiscal. Esta doctrina es perfectamente aplicable en el ámbito de los tributos locales y, como defiende María Dolores Arias Abellán ${ }^{41}$, no hay razón de peso que permita su modificación. Para estos postulados no puede utilizarse la reserva de ley ni la potestad originaria para establecer tributos para modificar una doctrina ajustada perfectamente al reparto de competencias y de «Poder», y por tanto de legitimación compartida entre el Estado y las Comunidades Autónomas, que se traduce en un reparto de competencias legislativas sobre las materias asumibles por las Comunidades Autónomas.

Las exigencias y garantías de la reserva de Ley en materia fiscal, tanto se pueden cumplir por Ley del Estado como por la Ley de la Comunidad Autónoma, aunque ésta esté infraordenada. El reparto normal de competencias así lo impone, sin que las sucesivas Sentencias del TC aporten razonamientos que justifiquen una competencia exclusiva del Estado en la materia: «...y es que hay que conjugar la reserva de ley con el reparto constitucional de competencias y aunque haya una reserva relativa a favor del Estado que debe contener un primer pronunciamiento sobre el tema, no puede derivarse de ello la ausencia de intervención legal por parte de las Comunidades Autónomas, pues una conclusión de este tipo significa desconocer los mecanismos de distribución de competencias que son tan constitucionales como la propia reserva de ley. Y esto es lo que parece olvidar el Tribunal Constitucional cuando, amparándose en la reserva de ley, declara que en esta materia, sólo puede ser respetada con ley estatal, olvidando que hacienda general no es hacienda total, que las bases son, eso, bases, y que la unidad del ordenamiento y la igualdad básica de los contribuyentes no pueden implicar una reserva absoluta de ley estatal en una materia en la que, además, los entes públicos distintos del Estado tienen atribuidas constitucionalmente potestad legislativa, de un lado $y$, de otro, potestad tributaria ${ }^{42}$.

\section{Separación entre competencias financieras y otras: la materia financiera no es una competencia}

La evolución y el cambio de criterio del TC se manifestará en la búsqueda y atribución de un fundamento constitucional y legal propio para la defi-

\footnotetext{
${ }^{41}$ Tributos Locales, núm. 31, julio de 2003.

${ }^{42}$ María Dolores Arias Abellán, Tributos Locales, no 31, julio de 2003, p. 24.
} 
nición y el establecimiento de la legislación financiera y tributaria estatal sobre las Corporaciones Locales y sobre las propias Comunidades Autónomas. A partir de la S 19/87, el TC ya no fundamentará las competencias del Estado sobre el Sistema Tributario Local en el régimen jurídico de las Administraciones Públicas —artículo 149.1.18 CE—; por el contrario, pasará a fundamentar su criterio de atribución de competencias normativas del Estado o de las Comunidades Autónomas sobre el sistema tributario local en el art. 133.1 y $2 \mathrm{CE}$, que constituye el verdadero fundamento constitucional de las competencias legislativas que el art. 106.1 LBRL reconoce a las potestades tributarias estatal y autonómica ${ }^{43}$. Este cambio radical tendrá efectos inmediatos en el legislador estatal, que fundamentará la competencia exclusiva del Estado sobre las Haciendas locales, junto con el clásico artículo 149.1.18, en los títulos sobre Hacienda general, y en la potestad originaria estatal para establecer tributos. El artículo 1 de la ley 39/88, de 28 de diciembre, a pesar de su obscuridad ${ }^{44}$, atribuye la exclusividad legislativa sobre Haciendas Autonómicas al Estado con fundamento en preceptos materiales, que no distribuyen competencias.

Para el TC, es la propia Constitución la que trata y regula por separado las «competencias financieras» de las Comunidades Autónomas y las otras competencias (no financieras) que éstas han asumido en los Estatutos de Autonomía o mediante otros procedimientos constitucionalmente idóneos. Esta separación aparece explícitamente en el art. 156.1 CE, que concede a las Comunidades Autónomas autonomía financiera «para el desarrollo y ejecución de sus competencias», lo financiero es un fenómeno instrumental del ejercicio de las competencias en sentido propio, no es una competencia material en sentido estricto, y no suele incluirse entre los listados de competencias de los Estado compuestos. Esta misma doctrina puede apreciarse en la previa STC 14/1986, Fto. Jco. $2^{\circ}$, que distingue y separa los conceptos de Hacienda y competencia por primera vez: «...la Hacienda regional no es tanto una competencia que se reconoce a las Comunidades Autónomas cuanto una exigencia previa o paralela a la propia organización autónoma».

En el desarrollo de la Constitución de 1978, el mismo camino siguen los Estatutos de Autonomía, que nunca incluyen ni mezclan las «competencias financieras» en las listas estatutarias de competencias, sino que las tratan separadamente al regular la Hacienda autonómica. El propio ejercicio de las competencias financieras y tributarias de las Comunidades Autónomas enumeradas en el art. 157.1 y 2 CE puede ser previamente regulado y ordenado por una ley orgánica (art. 157.3 CE), la Ley orgánica 6/83, de Financiación de las Comunidades Autónomas - tantas veces modificada como el sistema

\footnotetext{
${ }^{43}$ A. ZABALA RodríGUEZ-FARnos, «Consideraciones sobre un replanteamiento de las relaciones entre las Comunidades Autónomas y las Administraciones Locales: Aspectos sustantivos y tributarios», Palau $14, \mathrm{n}^{\circ} 19$.

${ }^{44}$ Luciano Parejo Alfonso, «Autonomía y Hacienda Local», Revista Catastro, enero de 1992, p. 7.
} 
COMPETENCIAS LEGISLATIVAS DEL ESTADO Y DE LAS COMUNIDADES AUTÓNOMAS...

de financiación autonómica - ocupa, por razón de la materia, un lugar especial en el ordenamiento jurídico: se integra en el bloque de constitucionalidad con el mismo rango que los propios Estatutos de Autonomía, que deberán interpretarse (Disposición Final LOFCA), en la resolución de los conflictos de competencias con el Estado, de conformidad o armonía con ella. Sirve de interpretación a los propios Estatutos, Disposición final de la LOFCA, y explica en parte las dificultades de las Comunidades Autónomas para diseñar un sistema tributario propio, tal y como se pone de manifiesto en las recientes Sentencias del TC 104/2000, de 13 de abril y 48/2004, de 25 de marzo.

Por esta vía abandona el TC su concepción original de las fuentes constitucionales del sistema tributario local, que partía de la premisa de que la Hacienda Local -incluido el Sistema Tributario Local- era una parte más del Régimen Local, cuya normación tenía que seguir el «canon» básico establecido en la materia por el Artículo 149.1.18 CE y, por lo tanto, seguir el esquema de distribución de competencias establecido en la constitución para el Régimen Jurídico de las Administraciones Públicas, para sostener que la Hacienda de las Comunidades Autónomas y de las Corporaciones Locales es un concepto distinto y separado de las propias competencias, por constituir y tratarse, en los Estados compuestos, de un instrumento previo y necesario para el funcionamiento y existencia de los poderes territoriales. Por ello, es responsabilidad del Estado la definición de todos sus elementos esenciales y básicos, la asignación de figuras impositivas a los distintos niveles territoriales, las relaciones entre todas ellas, y el establecimiento de todas las categorías jurídicas que permitan un tratamiento jurídico igual en todos los territorios.

\section{Funciones y alcance de la Reserva de Ley}

La doctrina constitucional sobre la reserva de ley en materia tribu-
taria, impuesta por el art. 31.3 CE, se extiende a la creación «ex novo»
de los tributos y a la configuración de los elementos esenciales de los
mismos (SSTC $37 / 1981$, fundamento jurídico $4^{\circ} ; 6 / 1983$, fundamento jurí-
dico $4^{\circ} ; 179 / 1985$, fundamento jurídico $3^{\circ} ; 19 / 1987$, fundamento jurídico $4^{\circ}$;
$221 / 1992$, fundamento jurídico $7^{\circ}$ y $14 / 1998$, fundamento jurídico 11 ; entre
otras).
El sentido que hay que reconocer en la reserva introducida por el art. 31.1
de la Constitución no puede entenderse, sin embargo, desligada de las con-
diciones propias al sistema de autonomías territoriales que la Constitución
consagra (art. 137) y específicamente de la garantía constitucional de la au-
tonomía de los municipios. En lo que al orden tributario importa, aquella
reserva de Ley resulta reiterada y especificada en los números 1 y 2 del art.
133 CE, que residencia la potestad originaria del Estado para, mediante Ley, 
establecer los tributos, y autoriza a las Comunidades Autónomas y a las Corporaciones Locales para que establezcan y exijan tributos, de acuerdo con la Constitución y las leyes.

La existencia de estos tres niveles de Hacienda — dos con auténtico poder legislativo- introduce por sí misma la cuestión sobre las competencias normativas de las Comunidades Autónomas sobre el Régimen Local. No cabe discutir su naturaleza - las Comunidades Autónomas tienen naturaleza política y aprueban normas con rango de Ley—, sí, la competencia de estas leyes de las Comunidades Autónomas para cumplir con los imperativos, requisitos y principios del artículo 31 de la Constitución en la definición del sistema tributario local ${ }^{45}$.

Para el TC, la reserva de ley sólo puede ser estatal en materia tributaria local. La razón estriba tanto en tener evidente tratamiento por completo separado del régimen de las competencias, como por las funciones que tiene que asumir ésta en los regímenes con distribución territorial del poder, en los que, STC 233/99 «...por esa función ad extra que tiene el principio de reserva de ley, es decir, como principio regulador de relaciones intersubjetivas entre los diferentes entes públicos territoriales dotados de poder y competencias constitucionales tributarias y, siendo esto así, el discurso debe trasladarse a los artículos 31.3 y 133.1 y 2 CE». La materia tributaria -el establecimiento y ordenación de los tributos- está al margen de la distribución competencial de nuestra $\mathrm{CE}$, no se considera una materia a distribuir entre distintos entes públicos, sino que es algo previo y diferente de ellas y, por lo tanto, hay que analizar los preceptos constitucionales que tienen eficacia respecto de los tributos ${ }^{46}$.

La evolución de la doctrina del TC sobre la titularidad de las competencias legislativas sobre los tributos locales culmina en la STC 233/99, que viene a negar abierta y expresamente competencia de las Comunidades Autónomas en la definición del Sistema Tributario Local. No sólo por esa función «ad extra» que resulta de aplicación en todos los Estados compuestos, la exclusión de las competencias de las Comunidades Autónomas en nuestro sistema constitucional de $1.978^{47}$, es una consecuencia de los principios rectores

\footnotetext{
${ }^{45}$ Zabala Gutiérrez-Fornos, Consideraciones sobre un replanteamiento..., ob. cit., nota 52.

${ }^{46}$ Procura así la Constitución integrar las exigencias diversas, en este campo, de la reserva de Ley estatal y de la autonomía territorial, autonomía que, en lo que a las Corporaciones Locales se refiere, posee también una proyección en el terreno tributario, pues éstos antes habrán de contar con tributos propios y sobre los mismos deberá la Ley reconocerles una intervención en su establecimiento o en su exigencia, según previenen los arts. 140 y 133.2 de la misma Norma fundamental, ello sin perjuicio de que, esta autonomía tributaria no sea plena (los tributos propios son sólo una de las varias fuentes de ingresos de las haciendas locales) y de que no aparezca la misma, desde luego, carente de límites, por el mismo carácter derivado del poder tributario de las Corporaciones Locales y porque también respecto de ellas, como no podía ser de otro modo, la autonomía hace referencia a un poder necesariamente limitado.
}

${ }^{47}$ STC 233/99 En el caso de que se trate de tributos que constituyan recursos propios de las Corporaciones Locales — carentes de potestad legislativa, aunque habilitadas por el art. 133.2 CE para 
de nuestro Estado Social y Democrático de Derecho que propugna como valores superiores la libertad...la igualdad, y el pluralismo político, artículo $1 \mathrm{CE}$.

La libertad y la igualdad en sus vertientes positivas: promover la igualdad y la libertad de los individuos y de los grupos en que se integran, artículo 9.2 CE; y en su vertiente negativa: todos los españoles son iguales ante la Ley sin que pueda prevalecer discriminación alguna... por cualquier otra condición o circunstancia personal o social, artículo $14 \mathrm{CE}$, desde el punto de vista de la acción política y de gobierno, obligan y vinculan a todos los poderes del Estado, y desde una perspectiva exclusivamente jurídica, presiden - especialmente, este artículo 14- la parte dogmática de nuestra Constitución de 1978, artículos 15 a 30, que podrán ser personalmente impetrados directamente ante los tribunales ordinarios, junto con el propio artículo 14 , por un procedimiento preferente y sumario, y por el recurso de amparo ante el TC, artículo 53.2 CE $\mathrm{CE}^{48}$. La protección constitucional de los derechos fundamentales culmina - artículo $81 \mathrm{CE}$ - con la conocida reserva de ley Orgánica del Estado, que garantiza un tratamiento igual y la propia efectividad de los derechos fundamentales.

Si los derechos de los ciudadanos y la actividad y orientación del poder político están presididos y regidos por los principios constitucionales de libertad e igualdad, que la Constitución de 1.978 garantiza con el establecimiento del principio de tutela judicial efectiva ${ }^{49}$, que viene a dar aplicación a los valores superiores de nuestro ordenamiento jurídico — preámbulo $\mathrm{CE}$ - , y a materializar cada día el pacto constitucional. Las obligaciones que impone la Constitución a todos los ciudadanos - fundamentalmente, contribuir al sostenimiento de los gastos públicos- también y en la misma medida vienen presididas por el principio de igualdad, y también en sus dos vertientes: ingreso y gasto, que se corresponden con los números 1 y 2 del artículo 31 CE.

Este artículo — que por su ubicación no está reservado a regularse por Ley Orgánica, ni se encuentra dentro del ámbito de protección especial y reforzada del artículo 53.2 CE—, por sus mandatos y principios — generalidad, igualdad, capacidad económica, asignación equitativa de los recursos públi-

establecerlos y exigirlos_, aquella reserva habrá de operarse necesariamente a través del legislador estatal, «cuya intervención reclaman los apartados 1 y 2 del artículo 133 de la Constitución», es también, en nuestro Estado constitucional democrático, como hemos puesto de relieve más arriba, una consecuencia de la igualdad y por ello preservación de la paridad básica de posición de todos los ciudadanos, con relevancia no menor, de la unidad misma del ordenamiento (art. 2 de la Constitución), unidad que - en lo que se refiere a la ordenación de los tributos y, de modo muy especial, de los impuestos - entraña la común prosecución, a través de las determinaciones que la Ley contenga, de objetivos de política social y económica en el marco del sistema tributario justo (art. 31.1) y de la solidaridad (art. 138.1) que la Constitución propugna.

${ }^{48}$ No será tan fácil modificar la regulación de este recurso para limitar el acceso al mismo.

49 Artículo. 24 CE, y STC 64 y 66 de 1984. 
cos- participa e impone los mismos valores superiores de libertad e igualdad de nuestra Constitución en el establecimiento y aplicación de los ingresos públicos, y en la propia ejecución del gasto, materias para las que reclama un tratamiento igual para los ciudadanos, que alcanza la misma especial y excepcional protección ${ }^{50}$.

La Autodisposición o aprobación/autorización de los ciudadanos sobre los propios impuestos y el resto de los gastos del Estado está en el origen de la democracia representativa moderna. Así aparece en la propia doctrina de la STC 233/99, para justificar el cumplimiento de las exigencias del principio de Reserva de Ley por el Pleno del Ayuntamiento. Esta Reserva de Ley en materia tributaria está presidida por los mismos principios de igualdad y generalidad que, en nuestra Constitución de 1978 y en la Jurisprudencia Constitucional, resultan de aplicación a los recursos en materia tributaria y financiera que, por esta acepción positiva, - - los recursos y las acciones que puedan entablarse por los ciudadanos-, en cuanto se refieran posibles lesiones de tales principios constitucionales: libertad, igualdad, capacidad económica, gozan del mismo régimen de protección que los derechos fundamentales reglados en los artículos 15 a 29 y $30 \mathrm{CE}^{51}$.

Existe un derecho fundamental a tener un tratamiento igual, a salvo de las propias competencias financieras de los Ayuntamientos, en cualquier parte del territorio del Estado Español. Los derechos históricos y los valores de las Autonomías Territoriales tienen que convivir con el principio de igualdad de todos los ciudadanos en el sostenimiento de los gastos públicos. Si el establecimiento de un sistema de garantías legales y judiciales de los derechos fundamentales expresa la unidad del Ordenamiento y la igualdad jurídica o de derecho de todos los ciudadanos, en los que reside la soberanía del Estado - artículo 1.2 CE-, en no menor medida la igualdad en el sostenimiento de los gastos públicos tiene que expresar la misma igualdad jurídica, que nace de la misma Soberanía.

\footnotetext{
${ }^{50}$ STC 193/2004, de 4 de noviembre de 2004, FJ $3^{\circ}$ : «la igualdad ha de valorarse, en cada caso, teniendo en cuenta el régimen jurídico sustantivo al ámbito de relaciones en que se proyecte. En la materia tributaria es la propia Constitución la que ha concretado y modulado el alcance de su art. 14 en un precepto, el art. 31.1, cuyas determinaciones no pueden dejar de ser tenidas aquí en cuenta, pues la igualdad ante la ley tributaria resulta indisociable de los principios de generalidad, capacidad, justicia y progresividad, que se enuncian en el último precepto constitucional citado (entre otras, SSTC 27/1981, de 20 de julio, FJ 4, y 46/2000, de 17 de febrero, FJ 4). Efectivamente, dicho precepto constitucional dispone que «todos contribuirán al sostenimiento de los gastos públicos de acuerdo con su capacidad económica mediante un sistema tributario justo inspirado en los principios de igualdad y progresividad que, en ningún caso, tendrá alcance confiscatorio». Esta recepción constitucional del deber de contribuir al sostenimiento de los gastos públicos según la capacidad económica de cada contribuyente configura un mandato que vincula, no sólo a los ciudadanos sino también a los poderes públicos (STC 76/1990, de 26 de abril, FJ 3) ya que, si los unos están obligados a contribuir de acuerdo con su capacidad económica al sostenimiento de los gastos públicos los otros están obligados, en principio, a exigir en condiciones de igualdad esa contribución a todos los contribuyentes cuya situación ponga de manifiesto una capacidad económica susceptible de ser sometida a tributación (STC 96/2002, de 25 de abril, FJ 7)».
}

${ }^{51}$ STC 179/85: «Una parte de la Jurisprudencia Constitucional en materia de sistema tributario local recae en recursos de amparo». 
COMPETENCIAS LEGISLATIVAS DEL ESTADO Y DE LAS COMUNIDADES AUTÓNOMAS...

\section{CONCLUSIONES}

El TC en la S 179/85 utiliza un concepto unitario del Régimen Local, como criterio de distribución de competencias legislativas en materia tributaria entre el Estado y las Comunidades Autónomas sobre el Régimen Local. El Sistema Tributario Local no disponía de otros criterios de distribución o atribución competencial y quedaba sujeto al «canon» constitucional establecido por el artículo 149.1.18 CE entre la legislación básica (Estatal) y la legislación de desarrollo (Comunitaria), la materia financiera no tiene para ésta doctrina un criterio o canon especial de reparto o de atribución de competencia entre el Estado y las Comunidades Autónomas, como legalmente se reconoció en el artículo 106 de la propia Ley 7/85,de 2 de abril, de Bases del Régimen Local.

La evolución posterior de la doctrina constitucional establecerá el criterio contrario: la Hacienda Local no es una materia más que pueda repartirse, es un concepto separado y previo al de materia y al de actividad administrativa, cuya regulación puede corresponder íntegramente al Estado por el juego de otros títulos competenciales, como son el de Hacienda General y el de garante de la suficiencia de las Haciendas Locales —artículos 149.1.14, y $142 \mathrm{CE}$ - Sin olvidar el propio juego del principio de reserva de ley junto con la potestad originaria para establecer tributos (artículos 133.1 y $31 \mathrm{CE}$ ), que más que atribuir competencia al Estado la presumen y le obligan — STC 19/87 - a encuadrar el ámbito de actuación que pueda corresponderle a los entes locales en la definición, establecimiento y aplicación de sus tributos propios, en el ejercicio de su autonomía constitucionalmente garantizada.

Se configura así la reserva de Ley del Estado como una especie de única, previa y necesaria garantía para la definición válida de los tributos locales, por tratarse del único vehículo apto para establecer un tratamiento tributario igual que exprese los valores y mandatos que impone el artículo 31 de la CE. La ley del Estado es la única hábil para cumplir con los principios de generalidad e igualdad que, al igual que en la regulación de los derechos fundamentales, sólo pueden cumplirse por Ley del Estado.

Sin embargo, hay que reconocer que no se ha dicho, -no ha habido ocasión- que sea inconstitucional una legislación estatal de Régimen local que atribuya, por supuesto con la debida predeterminación y encuadramiento, algún tipo de competencia legislativa sobre tributos e ingresos de las Corporaciones Locales a favor de las Comunidades Autónomas que la hubieran sobre el Régimen Local. Sin que pueda admitirse el libre establecimiento de sistemas tributarios locales distintos, según el grado de poder alcanzado por su respectiva autonomía territorial. En tal caso, la propia soberanía se habría territorializado en parte. 